\title{
Differential diagnosis of idiopathic inflammatory myopathies in adults - the first step when approaching a patient with muscle weakness
}

\author{
Piotr Szczęsny, Katarzyna Świerkocka, Marzena Olesińska \\ Department of Systemic Connective Tissue Diseases, National Institute of Geriatrics, Rheumatology, and Rehabilitation, Warsaw, \\ Poland
}

\begin{abstract}
Despite its misleading adjective, the most commonly used diagnostic criteria of idiopathic inflammatory myopathies (IIM) are applicable only after all other non-autoimmune muscle diseases have been excluded. It makes differential diagnosis the first step when approaching a patient with muscle weakness. This article is designed to list the most common conditions from which to differentiate in rheumatological care. In fact, many patients with the diseases described here have been initially misdiagnosed with IIM. For the purpose of this article, only the most commonly found and important conditions according to the authors are listed with the essence of information; other autoimmune muscle diseases, such as sarcoidosis and eosinophilic myositis, are not portrayed. The attached bibliography may serve as a source, when further exploration of a specific subject is needed.
\end{abstract}

Key words: myositis, differential diagnosis, myopathies in adults.

\section{Introduction}

Idiopathic inflammatory myopathies (IIM) are rare conditions with incidence ranging from 5.5 to 7.7 cases per million in developed countries. The list comprises polymyositis, dermatomyositis (including juvenile, amyopathic, and sine-dermatitis form), inclusion body myositis, immune-mediated necrotising myopathy (IMNM), and focal autoimmune myositis. In all of these conditions, due to abnormal reaction of the immune system, striated muscles become gradually inflamed with various intensities and irregular patterns. This reduces the number of rhabdomyocytes responding to each signal given by motor units to contract and consequently produces vast, rather symmetric muscle weakness of abrupt or subacute onset. Muscle weakness, however, is not synonymous with fatigue, although the latter occurs as a frequent accompanying sign of many autoimmune diseases, thus the physical examination should be targeted at differentiating these two. Fatigability of the muscles is not a core feature of inflammatory myopathies, either.
The essence of treatment for each type of IIM is immunosuppression, often with the use of glucocorticosteroids. Because this therapy itself is the cause of morbidity, it must be administered carefully. Knowing that delaying the treatment may cause irreversible damage, many doctors decide not to wait until all possible grounds of myopathy are excluded. However, as described below, in some cases administration of glucocorticosteroids may result in serious aggravation of symptoms.

\section{Toxic myopathies}

Many substances may be harmful to striated muscle fibres [1], among which the flagship examples are 3-hydroxy-3-methylglutaryl-coenzyme A reductase (HMGCR) inhibitors - statins. Usage of these drugs is more and more common in developed countries, and their efficacy in reducing mortality and disability from cardiovascular and cerebrovascular diseases is unquestionable; however, 5-20\% of patients complain of musculoskeletal symptoms that cause withdrawal of the therapy; 
0.4-0.9 per 10,000 person-years experience rhabdomyolysis [2], which can be fatal, if untreated.

The possible pathomechanism might be associated with overexpression of MHC-I in the rhabdomyocytes [3] and up-regulation of HMGCR [4]. Patients usually complain of proximal muscle weakness of the lower extremities and less commonly myalgia, which begins two weeks to four years after the initiation of the drug. Lipophilic statins, such as atorvastatin and simvastatin, are more likely to cause the myopathy than are hydrophilic agents. Laboratory tests may show significant elevation of creatine kinase (CK), proportional to the muscle damage, and myoglobinuria and renal damage can also occur. Electromyography shows typical myopathic units, and the histopathological picture presents with muscle fibre necrosis with prominent phagocytosis and small basophilic regenerating fibres; infiltration of inflammatory cells is scarce - in some instances only perivascular inflammation is present [5].

In most cases it is sufficient just to reduce the dose of the drug or switch to another substance; CK elevation usually normalises after 2-3 months but can persist for as long as 14 months. What is remarkable is that some patients develop anti-HMG-CoA antibodies and a chronic condition known as statin-induced immune-mediated necrotising myopathy (IMNM, formerly: necrotising autoimmune myopathy) [6], which requires immunosuppressive treatment, so follow-up in these patients is necessary [7]. The risk factors of statin-induced myopathy are presented in Table I.

Other drugs can also cause myopathy of varying severity, as presented in Table II. What is typical for this

Table I. Risk factors of statin-induced myopathy [1, 2]

\begin{tabular}{|l|}
\hline Risk factors of statin-induced myopathy \\
\hline $\begin{array}{l}\text { 1. Concomitant medications that interact with CYP3A4 } \\
\text { and increase serum statin concentration } \\
\text { (e.g. antibiotics, antifungals, calcium channel blockers, } \\
\text { antiretrovirals, antidepressants) }\end{array}$ \\
\hline $\begin{array}{l}\text { 2. Single nucleotide polymorphism (SNP) rs4363657 in the } \\
\text { SLCO1B1 gene on chromosome 12. Patients homozy- } \\
\text { gous for this SNP have above 15\% of risk of developing } \\
\text { myopathy within the first year of therapy }\end{array}$ \\
\hline 3. Female gender \\
\hline 4. Alcoholism \\
\hline 5. Hypothyroidism \\
\hline 6. Renal dysfunction \\
\hline 7. Liver dysfunction \\
\hline 8. Low BMI \\
\hline 9. Prior personal history of statin intolerance \\
\hline 10. Family history of statin intolerance \\
\hline
\end{tabular}

group is that the symptoms and CK levels usually normalise days-weeks after cessation of the drug.

Toxic myopathies include many that are caused by chronic alcohol abuse. Ethanol usually causes peripheral and central neuropathy, but it can also lead to acute necrotising or hypokalaemic myopathy, chronic alcoholic myopathy, asymptomatic alcoholic myopathy, and alcoholic cardiomyopathy. Acute necrotising myopathy occurs after intensive exposure to the substance, presents with muscle weakness, cramping, myalgia, and elevated CK levels, and can lead to acute renal failure. It presents with irritable myopathy on EMG, and muscle biopsy reveals widespread fibre necrosis. The condition resolves within weeks of abstinence. Acute hypokalaemic myopathy with potassium levels $<2 \mathrm{mmol} /$, elevated CK levels, and vacuolisation of muscle fibres in muscle biopsy is treated with careful potassium supplementation [8].

\section{Endocrinological causes of myopathy}

Steroid myopathy (caused by pituitary or adrenal gland hypersecretion, or iatrogenic) has to be considered in differential diagnosis at the beginning but also in the course of treatment as part of the spectrum of the patient's symptoms. This condition concerns about $50-80 \%$ of patients with endogenous Cushing syndrome. Among patients treated with high-dose steroids the incidence is difficult to measure. Exposure to equivalents of $30 \mathrm{mg}$ of prednisone per day causes proximal muscle weakness and atrophy especially of the lower extremities [9].

Myopathy usually begins after weeks of therapy but can appear even after a single dose. As well as the chronic condition related to endogenic or exogenic glucocorticoid excess, there is also a risk of developing acute myopathy with rhabdomyolysis, which may occur after 5-7 days after the onset of treatment with highdose glucocorticosteroids [10].

The most frequent symptom is reduction of muscle strength of the pelvic girdle and knee joint muscles, which results in declared difficulty climbing stairs and arising from low chairs. Women are more often affected than men, fluorinated synthetic glucocorticosteroids (dexamethasone, betamethasone, triamcinolone) are more likely to cause the condition than non-fluorinated agents, and an alternate-day regimen reduces the risk of myopathy [11]. Upper extremities are less affected. Distal, bulbar, neck muscles, and muscle stretch reflexes are normal, and myalgia is not present. CK levels are normal, EMG shows only subtle myopathic changes with no fibrillation potentials, and muscle biopsy reveals atrophy of mainly fast twitch type 2 fibres [12].

Muscle symptoms may be the predominant or the only clinical manifestation of hypothyroidism, and they 
Table II. ATC division of myopathy-causing substances [1, 7-9]

\begin{tabular}{|c|c|}
\hline A 02 - Drugs for acid related disorders & omeprazole, cimetidine \\
\hline C 01 - Cardiac therapy & amiodarone, procainamide \\
\hline C 07 - Beta blocking agents & labetalol \\
\hline C 10 - Lipid modifying agents & $\begin{array}{l}\text { statins: simvastatin }>\text { lovastatin }>\text { atorvastatin }>\text { rosuvastatin }>\text { pravastatin }> \\
\text { fluvastatin } \\
\text { other: gemfibrozil, niacin, ezetimibe, colevesam, fenofibrate }\end{array}$ \\
\hline $\begin{array}{l}\text { D } 07 \text { - Corticosteroids, dermatological } \\
\text { preparations }\end{array}$ & group: glucocorticosteroids (dexamethasone $>$ betamethasone $>$ triamcinolone) \\
\hline D 10 - Anti-acne preparations & isoretinion \\
\hline G 04 - Urologicals & finasteride \\
\hline J 05 - Antivirals for systemic use & zidovudine, lamivudine \\
\hline L 01 - Antineoplastic agents & vincristine, imatinib, gemcitabine, ipilimumab \\
\hline L 03 - Immunostimulants & interferon \\
\hline L 04 - Immunosuppressants & cyclosporine, tacrolimus, group: tumour necrosis-factors \\
\hline $\begin{array}{l}\text { M } 01 \text { - Anti-inflammatory and antirheu- } \\
\text { matic products }\end{array}$ & D-penicillamine \\
\hline M 04 - Antigout preparations & colchicine \\
\hline N 01 - Anaesthetics & propofol, cocaine \\
\hline N 02 - Analgesics & pethidine, pentazocine, pritramide \\
\hline N 03 - Antiepileptics & lamotrigine, phenytoin \\
\hline N 06 - Psychoanaleptics & L-tryptophan (eosinophilia myalgia, toxic oil syndrome syndrome), amphetamine \\
\hline N 07 - Other nervous system drugs & heroin \\
\hline P 01 - Antiprotozoals & hydroxychloroquine, chloroquine \\
\hline Toxicology & South American rattlesnake (Crotalus durissus), inhalative toluene \\
\hline
\end{tabular}

can precede biochemical hypothyroidism or occur simultaneously [13]. Elevation of CK and/or LDH levels in serum that accompanies hypercholesterolaemia, hyponatraemia, hyperprolactinaemia, or anaemia should implicate the test for TSH. In this condition, well-known symptoms of thyroid hormone deficiency: somnolence, cold intolerance, depressed mood, are accompanied by exercise intolerance, myalgia, cramps, stiffness, myoedema, especially of the calves, and carpal and tarsal tunnel syndromes. EMG shows primary myopathic changes, but only in half of the patients [14].

Muscle biopsy shows fibre size variation, type I fibre predominance, type 2 atrophy, internal nuclei, sporadic necrosis and regeneration [15], and disrupted mitochondria and glycogen accumulation [16], both beneath sarcolemmal membrane and between myofibrils; in a way, hypothyroidism induces metabolic myopathy. Accumulation of glycogen deposits disappear and CK values normalise within weeks of L-T4 therapy.

Excess of thyroid gland hormones can also be a cause of thyrotoxic myopathy. Muscle weakness is a complaint of up to $67 \%$ of patients with hyperthyroidism. This condition presents with proximal muscle weak- ness and heat intolerance. The shoulder girdle is most frequently affected, and in rare instances it presents with winging of the scapula. It more commonly affects elderly patients, more frequently men than women. Myalgia is not observed. Some patients develop reversible facial, bulbar, oesophagopharyngeal, and diaphragmatic muscle weakness producing various symptoms such as dysphagia and dyspnoea. Deep tendon reflexes may be normal or hyperactive, although the relaxation phase is often shortened. The severity is not associated with biochemical parameters, but with the duration of hyperthyroidism [17].

Creatine kinase levels are normal, EMG may show subtle non-specific changes, muscle biopsy reveals type 1 and 2 muscle atrophy, fatty infiltration, muscle fibre necrosis, and lymphocytic infiltration [18]. Usually the condition resolves 3-6 months after restoring euthyreosis; some patients report subjective improvement after treatment with a $\beta$-adrenergic blocker.

Diabetic myonecrosis, or diabetic muscle infarction, occurs in patients with long-lasting and poorly-controlled diabetes mellitus. It affects lower limbs in a focal manner, which makes it similar to focal myositis and 
may resemble relapse of myositis in patients chronically treated with glucocorticosteroids.

Only about 200 cases [19] were reported since it was first described in 1965. It presents as unilateral sudden pain and swelling of a muscle, usually of the thigh. CK levels are normal. Deep vein thrombosis should be excluded first by ultrasound. The key to the correct diagnosis, however, is MRI, which shows hyperintense signal on T2-weighted images and an isointense to hypointense signal on $\mathrm{T1}$-weighted images from the affected muscle as well as perifascial, perimuscular, and subcutaneous oedema. Muscle biopsy is contraindicated because it prolongs time to recovery [20]. The condition is well managed by bed-rest, non-steroidal anti-inflammatory drugs, and proper glycaemic control.

\section{Late-onset muscle dystrophies}

Facioscapulohumeral muscular dystrophy (FSHD) type 1 and type 2 are congenital myopathies inherited in autosomal dominant pattern. The disease is of variable penetrance and has an incidence of $1: 8,000$ to $1: 22,000$, which makes it the third most common dystrophy, after Duchenne muscular dystrophy and myotonic dystrophy. A classical clinical presentation is descending muscle weakness, as suggested by the name itself: in the first decade of life it is in the form of mild weakness of the orbital, mouth muscles (children sleeping with their eyes slightly open, difficulty whistling); the shoulder girdle is affected in the second decade of life (asymmetrical winged scapula, difficulty lifting objects above the head, straight clavicles, vertical or reversed anterior axillary fold, caved-in chest); lower abdominal (lumbar hyperlordosis), and pelvic girdle weakness may follow. However, up to $18 \%$ of patients may have facial muscles spared and late-onset cases (> 50 years old) have also been reported [21], which suggests acquired conditions such as IIM. CK is only mildly elevated - EMG shows discrete myopathic changes, and even MRI-guided muscle biopsy reveals the endomysial inflammatory cells surrounding intact fibres.

There is also a rapidly growing list of limb-girdle muscular dystrophies (LGMD), to-date having 21 subtypes, of which the most common are calpainopathy (LGMD2A), sarcoglycanopathy (LGMD2C-F), and dysferlinopathy (LGMD2B).

In the case of calpainopathy, lower limb weakness onset age ranges from 1 to 67 years, mean age 13 years, gradually affecting upper limbs within two years and leading to loss of ambulation within 20 years of its course. Winged scapula may be present, but no calf enlargement or cardiac complications are observed. Muscle biopsy shows severe endomysial fibrosis among other dystrophic changes (variation in fibre calibre, with focal necrosis and phagocytosis, and fibre splitting). Western blot studies may present abnormal calpain levels, but confirmatory genetic studies are essential for diagnosis.

The first symptoms of sarcoglycanopathy usually occur at around six years old, with onset age ranging from 1 to 30 years. Typical symptoms are true calf muscle hypertrophy (in contrast to pseudo-hypertrophy in Duchenne dystrophy), proximal weakness, frequent falls, Gowers manoeuvre, and rapid evolution to gait loss. Cardiac complications also occur, e.g. dilated cardiomyopathy. Muscle biopsy shows dystrophic changes, typically with no lobulated fibres.

Dysferlinopathy symptoms usually reveal themselves around the age of 19 years, but later onsets (to 58 years old) and subacute presentation have also been reported [22, 23], making it difficult to differentiate from inflammatory myopathy. Lower limb weakness is followed by upper limbs in various period of time (1-16 years); calf volume can be increased. CK levels are significantly elevated, resembling $I I M$, and MRI presents with hyperintensive patches very similar to polymyositis on STIR-weighted sequences [24]. Necrosis, phagocytosis, and regeneration can accompany typical dystrophic findings in muscle biopsy, which may point to IMNM.

It is crucial to ask the patient about previous family history of muscle diseases. It often requires asking the patients' parents to come for an examination. Genetic testing is necessary for diagnosis in patients with no family history of dystrophies. Although currently there is no available effective treatment for these conditions, symptoms can be alleviated by e.g. proper kinetic therapy, pain assessment, or surgical scapular fixation [25]. There is still some hope in genetic therapies that are being developed. Some authors suggest that patients may benefit from immunosuppressive treatment, glucocorticoids, or TNF-inhibitors, if started early [26].

\section{Lambert-Eaton myasthenic syndrome}

Of many forms of autoimmune neuromuscular junction diseases, perhaps the one worth mentioning is Lambert-Eaton myasthenic syndrome, which can be misdiagnosed with IIM for its lack of typical muscle fatigability, the presence of sicca symptoms, and frequently underlying neoplastic disease, because the syndrome is often associated with small-cell lung cancer. The disease results from the presence of antibodies directed against the voltage-gated calcium channels, preventing acetylcholine release from the presynaptic nerve terminals. It presents with slowly progressive symmetrical proximal muscle weakness with normal or decreased levels of muscle enzymes, but subacute onsets were also noted. 
Proximal muscle strength, deep tendon reflexes are depressed or even absent, but reappear after a 10-15 seconds of isometric contraction (post-activation facilitation), contrary to the typical muscle fatigability of myasthenia gravis. Cranial nerve involvement is not common, but ptosis or diplopia should strongly suggest the diagnosis. Autonomic symptoms can accompany musculoskeletal complains: dry mouth, erectile dysfunction, constipation, vision disturbances [27].

Distinctive electromyographic findings include reduced baseline amplitude of muscle action potential and significant increase after high-frequency stimulation or exercise; serological tests may serve as confirmation of the diagnosis. Chemotherapy and/or immunosuppression is the treatment of choice.

\section{Late-onset metabolic myopathies}

Glycogenosis type II (also known as Pompe disease) is an autosomal-recessive disease, known to occur in about $1: 50,000$ people, caused by the deficiency of acid $\alpha$-glucosidase (GAA). The severity of the disease varies from fatal neonatal (with very low enzyme level) to slowly progressive adult form. Symptoms of late-onset disease are weakness of proximal and axial muscles, often affecting the diaphragm and leading to respiratory insufficiency, and sometimes also affecting the heart muscle, causing cardiac hypertrophy and conduction abnormalities [28].

Considering symmetrical involvement of proximal muscles and insidious onset, the disease is often thought to be of autoimmune origin and is treated with corticosteroids. The histopathological hallmark of the disease is muscle fibre vacuolisation, which shows PAS (Periodic Acid-Schiff)-positive staining. Diagnosis is possible with blood spot enzymology and confirmatory genetic testing. Pompe disease is the only glycogenosis that has the possibility of pharmacological treatment with a recombinant GAA enzyme administered intravenously twice a week for at least one year [29]; however, treatment has to be initiated soon after the weakness or cardiological symptoms appear. The treatment does not reverse the disability of affected respiratory muscles.

Glycogenosis type $\vee$ (McArdle disease) results from deficiency of myophosphorylase and is characterised by fatigue and exercise-induced myalgia and episodic rhabdomyolysis, which can lead to myoglobinuria and renal failure. Proximal muscles, especially of the shoulder girdle, may also be affected later in life. Subsarcolemmal PAS-positive blebs can be found in the muscle biopsy, but the diagnosis is confirmed by histoenzymatic stain for the phosphorylase and a genetic test. Patients alleviate the symptoms by using the "second-wind" phe- nomenon: mild aerobic exercise 10 minutes before the exertion raises the availability of blood-borne glucose in muscles and reduces myalgia [30]. Current treatment recommendations comprise kinetic therapy, a carbohydrate-rich diet, and vitamin B6 supplementation.

Neutral lipid storage disease with myopathy (NLSD-M) presents as slowly progressive proximal muscle weakness affecting the upper limbs, cardiomyopathy, and elevated CK level resembling IIM, accompanied by hepatic steatosis, hypertriglyceridaemia, diabetes mellitus, and sensorineural hearing loss [31].

Muscle biopsy shows neutral lipid storage with the appearance of vacuolated fibres and increased OilRed-O droplets, especially in the atrophic fibres. Peripheral blood microscopic smear test shows Jordan's anomaly - lipid droplets in the cytoplasm of leukocytes. There is currently no effective treatment.

Multiple acyl-CoA dehydrogenase deficiency (MADD) is a mitochondrial myopathy that is characterised by proximal muscle weakness, high CK levels, vomiting, and hypoglycaemia [32]. Additional laboratory tests show low free carnitine but elevated acyl-carnitines; muscle biopsy presents lipid storage myopathy. The condition responds well to riboflavin and carnitine supplementation.

Carnitine palmitoyl transferase II (CPT-II) deficiency is another mitochondrial myopathy, which produces cramps, myalgia, and exercise intolerance. Episodes of rhabdomyolysis, high CK levels, and myoglobinuria occur, triggered by prolonged exercise, cold, fever, fasting, or anaesthetic drugs. It can be managed by intravenous glucose administration but can require dialysis in some severe cases. Muscle examination reveals fibres with small vacuoles and lipid droplet accumulation. Adopting appropriate lifestyle recommendations and diet [33] prevents the episodes of rhabdomyolysis.

\section{Infections}

Myositis can also be caused by infectious pathogens: viral, bacterial, fungal, and parasitic. Usually it is mild or of limited distribution; however, the viral infections are the ones that are best known to produce generalised disease [34].

Myalgia is a common complaint of patients having a common influenza infection, it can follow or precede other symptoms, such as cough, headache, rhinorrhoea, viral pneumonia, myocarditis, and meningoencephalitis. Myositis can occur approximately three days after the onset of symptoms of infection (0-18 days), it usually starts as calf pain and difficulty with difficulty in ambulation, and it occurs more often in children and in type B 
infection [35]; however, it is type A that is more often associated with rhabdomyolysis.

Muscle enzyme levels are elevated, myopathic changes are noted in the EMG, and muscle biopsy, when performed, can reveal degeneration and necrosis with small inflammatory cells infiltration [36], as in IMNM. The course of the disease is self-limiting, results within three days (1-30 days). There is no proven effective treatment except for symptomatic management.

Similar cases have been reported to be associated with coxsackieviruses type A and B [37], enteric cytopathogenic human orphan (ECHO) viruses [38], adenoviruses [39], and respiratory syncytial virus [40].

Human immunodeficiency virus (HIV) can cause nemaline myopathy and can be a triggering factor of amyotrophic lateral sclerosis, bibrachial amyotrophic diplegia, and inflammatory muscle diseases like IMNM at any time in its course [41]. Sporadic late-onset nemaline myopathy associated with HIV infection is characterised by subacute proximal muscle weakness of the limbs; often neck, pharyngeal and respiratory muscles are affected as well. There have been reports on progressive external ophthalmoplegia [42].

Tendon reflexes are depressed and fasciculations may appear. CK levels are normal, but laboratory tests show hypergammaglobulinaemia of monoclonal or polyclonal character, which normalises during highly active antiretroviral therapy (HAART). Muscle biopsy shows characteristic red rods of actin with Gomori stain. It is justified to screen myositis patients for HIV infection because these myopathies are usually of good prognosis, and patients respond well to HAART and immunosuppressive treatment, like glucocorticoids and intravenous immunoglobulins [41]. As it has been described above, however, antiretroviral therapy itself can cause musculoskeletal adverse effects.

There have also been reports of myositis caused by human T-cell lymphotropic virus type 1 (HTLV-1) [43], hepatitis B and C [44], cytomegalovirus [45], Epstein-Barr virus [46], herpes simplex virus [47], varicella-zoster virus [48], and dengue [49].

Bacterial pyomyositis presents as local pain and oedema of 'woody' texture, which turns into severe pain and fever and finally sepsis within 2-3 weeks. Any skeletal muscle can be affected, although the most vulnerable are the lower extremities, because the condition is thought to be associated with local trauma. Diagnosis can be difficult because many patients are from the immunosuppressed or HIV-positive group; however, the inflammatory markers that are more elevated than the muscle enzymes. 60-90\% of cases are caused by Staphylococcus aureus, secondly Streptococcus pneumoniae, but type B, C, and G streptococci, and less commonly
Clostridium spp., Mycobacterium spp., are also known to produce the condition. In its early stages, it can be confirmed by ultrasound, CT, or MRI and treated with empirical antibiotics covering firstly $\mathrm{S}$. aureus (remembering of risk of MRSA), but puncture, drainage, or surgical open procedure often become necessary in later stages [50].

Despite the fact that mild arthralgia and myalgia often occur in the course of Lyme borreliosis (and post-borreliosis), Lyme myositis is usually localised and appears simultaneously with other symptoms like monoarthritis and typical skin lesions. CK is normal or only mildly elevated, but generalised myositis and rhabdomyolysis cases have also been reported [51]. Histopathology shows interstitial muscle macrophages and $\mathrm{T}$ helper cell infiltrates near small blood vessels, often associated with fibre degeneration. Silver stains for spirochetes sometimes visualise the microorganisms in affected tissue. Penicillin, cephalosporins, and tetracyclines are effective treatment options.

Some parasitic myopathies tend to be more diffuse in nature. Katayama syndrome, caused by Schistosoma spp., presents as generalised myalgia, reduction of muscle mass, and weakness (especially of the pelvic diaphragm, causing rectal prolapse) accompanied by fever, chills, cough, headache, abdominal tenderness, and urticaria. Kato-Katz smear of stool is helpful for diagnosis, and treatment comprises of praziquantel and glucocorticosteroids. Muscle involvement occurs in $75 \%$ of patients with neurocysticercosis, caused by Taenia spp. Diffuse disease presents as calcifications in the muscle bundles in the thighs or arms.

Fungal myositis should be suspected when fever, rash, and myalgia [52] occur in immunosuppressed patients. The most common causative pathogen is Candida tropicalis or other Candida spp. Muscle MRI shows numerous microabscesses, and the disease is confirmed by the presence of yeast and pseudohyphae in muscle biopsy. Mortality rates are high [53].

\section{Conclusions}

Retrospective studies show that elevated CK levels are found in as many as $8 \%$ of patients seeking healthcare professional aid, of which rheumatological conditions account for only $0.8 \%$ of cases [54]. What is more, $45 \%$ of patients referred to rheumatologists are finally not confirmed to have IIM. The true reason for the illness is found to be caused by drugs in $8 \%$, infection in $6 \%$, and trauma in $5 \%$; of note, $6 \%$ of patients have only idiopathic CK-aemia [55]. In Figure 1 the all-causes myopathy is shown. 


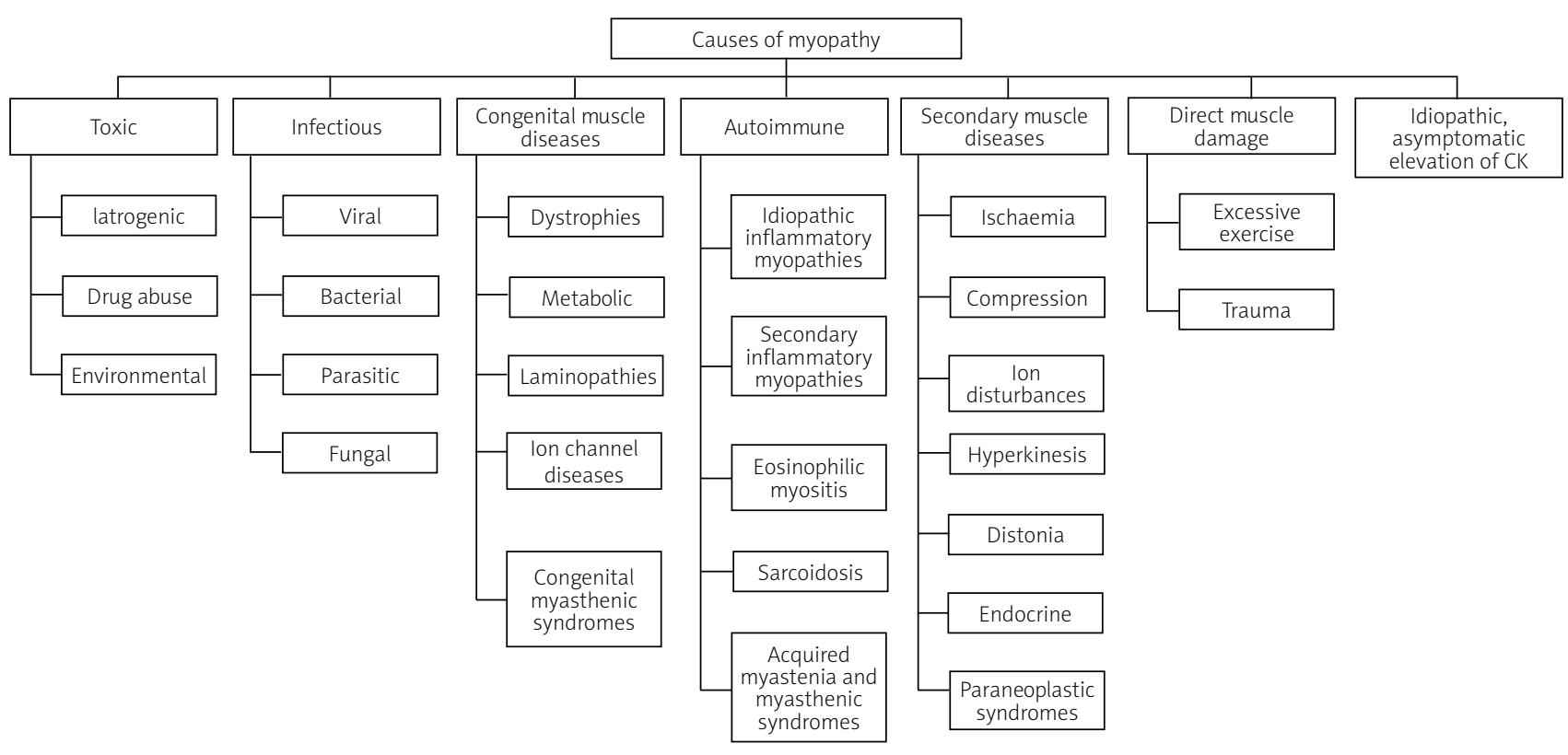

Fig. 1. Diagram of causes of myopathy.

Looking back at the IIM Peter and Bohan diagnostic criteria, we can see that neither of the five is distinctive for autoimmune disease. Several symptoms, however, serve in favour: subacute onset, skin lesions (e.g. Gottron's papules, heliotrope rashes, photosensitivity), symmetrical, proximal muscle groups involvement, Raynaud's phenomenon, arthritis, and interstitial lung disease. Certainly, pathological muscle examination may play a crucial role in diagnosis, hence the necessity for guided biopsy techniques. Several symptoms should raise caution or even lead away from diagnosis of IIM: very slow and gradual progression or variable dynamics of symptoms, very early onset, a similar family history, weakness or myalgia related to exercise and fasting, fatigability, fasciculations, asymmetrical distribution, facial involvement, accompanying cataract or diabetes, severe myalgia, or remarkedly elevated inflammatory markers. One condition, however, never entirely excludes another. Any previously existing muscular disease is a risk factor for developing inflammatory myopathy, and any myopathy can appear independently during the course of the disease, impeding the assessment of disease activity.

The rights revenue was paid by Stowarzyszenie Zbiorowego Zarzadzania Prawami Autorskimi Twórców Dziet Naukowych i Technicznych KOPIPOL of Kielce from fees collected pursuant to Article 20 and Article $20^{1}$ of the Copyright and Neighbouring Rights Act.
Wynagrodzenie autorskie sfinansowane zostato przez Stowarzyszenie Zbiorowego Zarzadzania Prawami Autorskimi Twórców Dziet Naukowych i Technicznych KOPIPOL z siedziba w Kielcach z opłat uzyskanych na podstawie art. 20 oraz art. $20^{1}$ ustawy o prawie autorskim i prawach pokrewnych.

The authors declare no conflict of interest.

\section{References}

1. Pasnoor M, Barohn RJ, Dimachkie MM. Toxic myopathies. Neurol Clin 2014; 32: 647-670.

2. Silva M, Matthews ML, Jarvis C, et al. Meta-analysis of drug-induced adverse events associated with intensive-dose statin therapy. Clin Ther 2007; 29: 253-260.

3. Needham M, Fabian V, Knezevic W, et al. Progressive myopathy with up-regulation of $\mathrm{MHCl}$ associated with statin therapy. Neuromuscul Disord 2007; 17: 194-200.

4. Mammen AL, Chung T, Christopher-Stine L, et al. Autoantibodies against 3-hydroxy-3-methylglutaryl-coenzyme A reductase in patients with statin-associated autoimmune myopathy. Arthritis Rheum 2011; 63: 713-721.

5. Mohassel P, Mammen AL. The spectrum of statin myopathy. Curr Opin Rheumatol 2013; 25: 747-752.

6. Grable-Esposito P, Katzberg HD, Greenberg SA, et al. Immune-mediated necrotizing myopathy associated with statins. Muscle Nerve 2010; 41: 185-190.

7. Mammen AL. Necrotizing myopathies: beyond statins. Curr Opin Rheumatol 2014; 26: 679-683.

8. Preedy VR, Ohlendieck K, Adachi J, et al. The importance of alcohol-induced muscle disease. J Muscle Res Cell Motil 2003; 24: 55-63. 
9. Khaleeli AA, Edwards RH, Gohil K, et al. Corticosteroid myopathy: a clinical and pathological study. Clin Endocrinol 1983; 18: 155-166.

10. Hanson P, Dive A, Brucher JM, et al. Acute corticosteroid myopathy in intensive care patients. Muscle Nerve 1997; 20: 1371-1380.

11. Faludi G, Gotlieb J, Meyers J. Factors influencing the development of steroid-induced myopathies. Ann N Y Acad Sci 1966; 138: 62-72.

12. Lacomis D, Giuliani MJ, Van Cott A, Kramer DJ. Acute myopathy of intensive care: clinical, electromyographic, and pathological aspects. Ann Neurol 1996; 40: 645-654.

13. Wood-Allum CA, Shaw PJ. Thyroid disease and the nervous system. Handb Clin Neurol 2014; 120: 703-735.

14. Duyff RF, Van den Bosch JV, Laman DM, et al. Neuromuscular findings in thyroid dysfunction: a prospective clinical and electrodiagnostic study. J Neurol Neurosurg Psychiatry 2000; 68: 750-755.

15. Rodolico C, Toscano A, Benvenga S, Vita G. Skeletal muscle disturbances may precede clinical and laboratory evidence of autoimmune hypothyroidism. J Neurol 1998; 245: 555-556.

16. McDaniel HG, Pittman CS, Oh SJ, Di Mauro S. Carbohydrate metabolism in hypothyroid myopathy. Metabolism 1977; 26: 867-873.

17. Amato AA. Endocrine myopathies and toxic myopathies. In: Neuromuscular Function and Disease: Basic, Clinical, and Electrodiagnostic Aspects, Brown WF, Bolton CF, Aminoff MJ (eds.), vol. 2. W.B. Saunders, Philadelphia 2002: 1399-1402.

18. Celsing F, Blomstrand E, Melichna J, et al. Effect of hyperthyroidism on fibre area, glycogen content, and enzyme activity in human skeletal muscle. Clin Physiol 1986; 6: 171-181.

19. Iyer SN, Drake AJ III, West RL, et al. Diabetic muscle infarction: a rare complication of long-standing and poorly controlled diabetes mellitus. Case Rep Med 2011; 2011: 407921.

20. Barohn RJ, Kissel JT. Case of the month: painful thigh mass in a young woman: diabetic muscle infarction. Muscle Nerve 1992; 15: 850-855.

21. Pastorello E, Cao M, Trevisan CP. Atypical onset in a series of122 cases with facioscapulohumeral muscular dystrophy. Clin Neurol Neurosurg 2012; 114: 230-234

22. Paradas C, González-Quereda L, De Luna N, et al. A new phenotype of dysferlinopathy with congenital onset. Neuromus cul Disord 2009; 19: 21-25.

23. Takahashi T, Aoki M, Suzuki N, et al. Clinical features and a mutation with late onset of limb girdle muscular dystrophy 2B. J Neurol Neurosurg Psychiatry 2013; 84: 433-440.

24. Degardin A, Morillon D, Lacour A, et al. Morphologic imaging in muscular dystrophies and inflammatory myopathies. Skeletal Radiol 2010; 39: 1219-1227.

25. Cotta A, Carvalho E, da-Cunha-Júnior AL, et al. Common recessive limb girdle muscular dystrophies differential diagnosis: why and how? Arq Neuro-Psiquiatr 2014; 72: 721-734.

26. Tidball JG, Wehling-Henricks $M$. Damage and inflammation in muscular dystrophy: potential implications and relationships with autoimmune myositis. Curr Opin Rheumatol 2005; 17: 707-713.
27. O'Suilleabhain P, Low PA, Lennon VA. Autonomic dysfunction in the Lambert-Eaton myasthenic syndrome: serologic and clinical correlates. Neurology 1998; 50: 88.

28. Schüller A, Wenninger S, Strigl-Pill N, Schoser B. Toward deconstructing the phenotype of late-onset Pompe disease. Am J Med Genet C: Semin Med Genet 2012; 160: 80-88.

29. Cupler EJ, Berger KI, Leshner RT, et al.; AANEM Consensus Committee on Late-onset Pompe Disease. Consensus treatment recommendations for late-onset Pompe disease. Muscle Nerve 2012; 45: 319-333.

30. Lucia A, Quinlivan R, Wakelin A, et al. The 'McArdle paradox': exercise is a good advice for the exercise intolerant. $\mathrm{Br} J$ Sports Med 2013; 47: 728-729.

31. Fischer J, Lefevre C, Morava E, et al. The gene encoding adipose triglyceride lipase (PNPLA2) is mutated in neutral lipid storage disease with myopathy. Nat Genet 2007; 39: 28-30.

32. Liang WC, Nishino I. Lipid storage myopathy. Curr Neurol Neurosci Rep 2012; 11: 97-103.

33. Ørngreen MC, Ejstrup R, Vissing J. Effect of diet on exercise tolerance in carnitine palmitoyltransferase II deficiency. Neurology 2003; 61: 559-561.

34. Crum-Cianflone NF. Bacterial, fungal, parasitic, and viral myositis. Clin Microbiol Rev 2008; 21: 473-494

35. Tabbutt S, Leonard M, Godinez RI, et al. Severe influenza B myocarditis and myositis. Pediatr Crit Care Med 2004; 5: 403406.

36. Davis LE, Kornfeld M. Experimental influenza B viral myositis. J Neurol Sci 2001; 187: 61-67.

37. Fodili F, van Bommel EF. Severe rhabdomyolysis and acute renal failure following recent Coxsackie B virus infection. Neth J Med 2003; 61: 177-179.

38. Jehn UW, Fink MK. Myositis, myoglobinemia, and myoglobinuria associated with enterovirus echo 9 infection. Arch Neurol 1980; 37: 457- 458.

39. Sakata H, Taketazu G, Nagaya K, et al. Outbreak of severe infection due to adenovirus type 7 in a paediatric ward in Japan. J Hosp Infect 1998; 39: 207-211.

40. Naylor CD, Jevnikar AM, Witt NJ. Sporadic viral myositis in two adults. CMAJ 1987; 137: 819-821.

41. Johnson RW, Williams FM, Kazi S, et al. Human immunodeficiency virus-associated polymyositis: a longitudinal study of outcome. Arthritis Rheum 2003; 49: 172-178.

42. Wright RA, Plant GT, Landon DN, et al. Nemaline myopathy: an unusual cause of ophthalmoparesis. J Neuroophthalmol 1997; 17: 39-43.

43. Morgan OS, Rodgers-Johnson P, Mora C, Char G. HTLV-1 and polymyositis in Jamaica. Lancet 1989; 2: 1184-1187.

44. Nojima T, Hirakata M, Sato S, et al. 2000. A case of polymyositis associated with hepatitis B infection. Clin Exp Rheumatol 2000; 18: 86-88.

45. Maeda M, Maeda A, Wakiguchi $\mathrm{H}$, et al. Polymyositis associated with primary cytomegalovirus infection. Scand J Infect Dis 2000; 32: 212-214.

46. Uchiyama T, Arai K, Yamamoto-Tabata T, et al. Generalized myositis mimicking polymyositis associated with chronic active Epstein-Barr virus infection. J Neurol 2005; 252: 519-525. 
47. Schlesinger JJ, Gandara D, Bensch KG. Myoglobinuria associated with herpes-group viral infections. Arch Intern Med 1978 138: 422-424.

48. Badilla J, Dolman PJ. Orbital myositis involving the oblique muscles associated with herpes zoster ophthalmicus. Ophthal Plast Reconstr Surg 2007; 23: 411-413.

49. Finsterer J, Kongchan K. Severe, persisting, steroid-responsive Dengue myositis. J Clin Virol 2006; 35: 426-428.

50. Crum-Cianflone NF. Bacterial, fungal, parasitic, and viral myositis. Clin Microbiol Rev 2008; 21: 473-494.

51. Jeandel C, Perret C, Blain H, et al. Rhabdomyolysis with acute renal failure due to Borrelia burgdorferi [letter]. J Int Med 1994; 235: 191-192.
52. Jarowski Cl, Fialk MA, Murray HW, et al. Fever, rash, and muscle tenderness. Adistinctive clinical presentation of disseminated candidiasis. Arch Intern Med 1978; 138: 544-546.

53. Diggs CH, Eskenasy GM, Sutherland JC, Wiernik PH. Fungal infection of muscle in acute leukemia. Cancer 1976; 38: 17711772.

54. Grunau BE, Pourvali R, Wiens MO, et al. Characteristics and thirty-day outcomes of emergency department patients with elevated creatine kinase. Acad Emerg Med 2014; 21: 631-636.

55. Leverenz D, Zaha O, Crofford LJ, Chung CP. Causes of creatine kinase levels greater than $1000 \mathrm{IU} / \mathrm{L}$ in patients referred to rheumatology. Clin Rheumatol 2016; 35: 1541-1547. 